\author{
REVISTA ECONOMÍA \\ Vol. 66, N. ${ }^{\circ}$ IO4 (noviembre 20I4), IO5-II4
}

\title{
LOS LEGADOS DE MANUEL AGUSTÍN AGUIRRE
}

\author{
JOSÉ MONCADA SÁNCHEZ \\ Exrector, Universidad Central del Ecuador
}

\begin{abstract}
Discurso pronunciado por el economista José Moncada Sánchez, exrector de la Universidad Central del Ecuador, con motivo de un homenaje póstumo al doctor Manuel Agustín Aguirre, realizado por diversas instituciones culturales, sociales y políticas el día 20 de noviembre de 1992, en la Casa de la Cultura Ecuatoriana «Benjamín Carrión», en la ciudad de Quito.
\end{abstract}

Nos hemos reunido esta noche para rendir un sincero homenaje de afectuoso recuerdo a uno de los hombres más valiosos de nuestro país, a un luchador revolucionario, a un intelectual que abrazó desde muy temprana edad la causa de los trabajadores y del socialismo, a Manuel Agustín Aguirre.

Por cierto, resulta ciertamente difícil identificar y valorar el aporte de un hombre a la vida intelectual, política, cultural, a la historia de un país, si es que no se inserta a ese hombre en las condiciones materiales, en el contexto social y político en el que le correspondió pensar y actuar. El mismo Aguirre solía decir que:

El individuo no nace del aire, es producto de la sociedad, de una clase social que lo forma, lo crea y muchas veces llega a expresar algunas cualidades de su pueblo.

Manuel Agustín Aguirre nació en julio de 1903, perteneció a una típica familia de las capas medias que a muy temprana edad perdió a sus padres, lo cual debió enfrentarlo a una vida de lucha y duros esfuerzos. Realizó sus estudios de secundaria en el Colegio Bernardo Valdivieso donde al distinguirse como excelente estudiante y, según él lo anota, para ayudarse en los estudios de muchacho sin recursos fue nombrado como Ayudante del Gabinete de Física. Allí empezó a ejercer una de sus pasiones, la de educar. Posteriormente, siguió sus estudios universitarios en la Facultad de Derecho de la Junta Universitaria de Loja y en la Facultad de Jurisprudencia de la Universidad Central del Ecuador.

Durante la juventud de Aguirre, muchos acontecimientos ocurrieron en el mundo, en América Latina y en nuestro país, que fueron marcando su formación y modulando su personalidad. La revolución de Cárdenas en el México de 1910, la lucha antimperialista de Sandino en Nicaragua, la Reforma Universitaria de Córdova en 1918, la Revolución de Octubre de 1917, la Primera Guerra Mundial, la gran crisis capitalista de 1929-32.

En el orden nacional, los impactos de la crisis capitalista mundial que se expresaron en la brusca caída de las exportaciones de cacao, la descomposición de la oligarquía financiera del litoral, la masacre de los trabajadores el 15 de noviembre de 1922 en Guayaquil, la Revolución 
Juliana, la modernización del Estado durante el gobierno de Ayora, la Revolución de Mayo de 1944. Sin duda, todos estos hechos fueron ejerciendo una significativa influencia en la formación ideológica y política del joven Aguirre, que lo impulsaron a formar uno de los primeros núcleos socialistas del país: Vanguardia Socialista. Y es que acontecimientos como los mencionados, conmovieron a la juventud de aquellos años. No de otra manera se explica que hombres de tanto valor como José de la Cuadra, Enrique Gil Gilbert, Jorge Carrera Andrade, Angel F. Rojas, Pablo Palacio, Clotario Maldonado, Jorge Hugo Rengel, Joaquín Gallegos Lara hayan también abrazado la causade la política. El mismo Aguirre decía que Se necesitaba tener piel de elefante para cruzarse de brazos, para no sentir las angustias, el dolor, el asesinato de un pueblo. (Memoria del Homenaje al señor doctor Manuel Agustín Aguirre, p. 15).

Su adhesión a la causa del socialismo hizo que llegara a ocupar la Secretaría General de este partido durante varias ocasiones. Fue diputado funcional por los trabajadores, vicepresidente de la Asamblea Constituyente en 1944, fundador de la Escuela de Economía de la Universidad Central, decano de la Facultad de Ciencias Económicas, vicerrector y rector de la Universidad Central. Es decir, en Aguirre se fundieron los roles de luchador social, de educador y de combatiente por el socialismo, pues junto a su militancia partidaria, mantuvo siempre una constante y directa comunicación con las organizaciones de trabajadores del Ecuador y de varios países del mundo.

Autor de varios libros y ensayos, Aguirre fue un hombre de formación marxista, un teórico, un ideólogo cuyo quehacer político estuvo básicamente motivado por las exigencias de transformación revolucionaria del Ecuador. No fue un luchador ganado por el pragmatismo ni por las demandas de superación de cuestiones específicas en el marco del capitalismo.

Estuvo presto a denunciar con la palabra y con el ejemplo toda forma de oportunismo y de corrupción. Acaso este conjunto de hechos sea la base para que muchas personas lo recuerden a Aguirre como un personaje en cierta forma rígido, inflexible, un tanto ajeno al tratamiento de los temas coyunturales del Ecuador. Lo que ocurre, sin embargo, es que Aguirre jamás perdió de vista el objetivo final; nunca se dejó confundir respecto al verdadero carácter de la lucha de los trabajadores en un país como el Ecuador, ni fue afecto a la negociación de los principios. Esa aparente rigidez fue un rasgo de su personalidad política y moral que de ninguna manera significó abandono del sentido de la realidad o desprecio por la coyuntura política.

Pues bien, así perfilados la personalidad política y el escenario en el cual Aguirre actuó, parece conveniente reparar ahora en los aspectos más salientes de su pensamiento y de su acción que, como verdaderos legados al pueblo ecuatoriano y al socialismo, estamos en la obligación de continuar quienes somos afectos al cambio revolucionario del Ecuador. Hacer esto nos parece vital para que nuestro homenaje a este excepcional ecuatoriano, no sea un acto simplemente luctuoso, apologético y ritual, sino un esfuerzo para tratar de entender los problemas del mundo y del país en el cual nos ha correspondido vivir.

\section{SU LEGADO MARXISTA}

Aguirre supo interpretar la realidad mundial, latinoamericana y nacional apoyándose en el marxismo. De él se valió para comprender que allá por la década de los cincuenta, cuando 
era común que a la formación social ecuatoriana se la calificara de feudal, Aguirre la caracterizara como capitalista.

Y no se trataba, ciertamente de una cuestión puramente teórica o académica. Era, más bien la base para definir incluso líneas de acción tácticas. Si el Ecuador era semifeudal o semicapitalista, la lucha por el socialismo aún debía esperar, una vez que la burguesía tenía una misión histórica que cumplir, la de lograr el desarrollo de un capitalismo autónomo, donde se alcance un crecimiento acelerado de las fuerzas productivas, donde se modernicen las relaciones sociales de producción, donde se expanda cuantitativamente la clase trabajadora como la fuerza social y política capaz de construir un nuevo ordenamiento económico y social.

En la perspectiva de quebrar con esta apreciación, Aguirre reconoció que el capitalismo en nuestro país surgió y se desarrolló cuando el imperialismo ya había hecho su aparición en todo el mundo; siendo precisamente ese imperialismo la traba para el desarrollo de un capitalismo autónomo e independiente en América Latina y el Ecuador.

Nuestra pseudoburguesía - dice Aguirre en uno de sus trabajos de mayor difusión- como la de los demás países subdesarrollados de Latinoamérica, se ha mostrado incapaz de realizar la destrucción de los rezagos feudales que nos encadenan al pasado, porque su composición no le permitía ni permite tal misión histórica. (América Latina y el Ecuador, 1959). Por ello, Aguirre subrayaba que:

En Latinoamérica como en el Ecuador, las clases burguesas no han podido llevar a cabo su misión histórica que les correspondía, debido a su especial composición y peculiaridades; [mas al reconocer aquello, no es que Aguirre ignorara que] la etapa transitoria que inicia la revolución hasta llegar, andando mucho, al socialismo, se desentienda de ejecutar algunas tareas que la burguesía no pudo realizar oportunamente.

Marxismo viviente, creativo, fresco, científico. Pero es que Aguirre no era un simple repetidor del marxismo ni lo usaba de manera mecanicista, sino como método para acercarse a la realidad a fin de comprenderla de mejor manera para transformarla.

Decía, por ejemplo, refiriéndose a quienes tratan de implantar mecánicamente las formaciones económicas, que son personas que quieren encontrar en América Latina una sucesión rectilínea de los modos de producción y de las formaciones sociales y para ello muchas veces meten a empujones la realidad de su teoría como en el lecho de Procusto. (Marx ante América Latina, 1985, p. 192). Mientras que, refiriéndose a la economía nacional anotaba:

Nuestra economía ecuatoriana, como la de los demás pueblos poco desarrollados de América Latina, constituye un gigantesco museo de historia económica universal, en el que se amontonan, unidas y superpuestas, todas las formas económicosociales por las que ha pasado la Humanidad. (Íb.,12).

Así pues, en la defensa de un marxismo fresco, viviente, científico, Aguirre supo insurgir contra las críticas que desde varias vertientes pero especialmente desde la revisionista y oportunista, pretendían despojar al marxismo de su validez científica y de su significación histórica.

Inclusive, Aguirre supo comprender y aceptar que múltiples cambios en el acontecer mundial, no fueron previstos por Marx. Sostener lo contrario habría sido profundamente erróneo 
y antimarxista. De ahí que frecuentemente gustaba de repetir que el marxismo era y es una ciencia en movimiento que no se acabó con Marx, Engels o Lenin, sino que se ha enriquecido con el aporte de tantos y tantos cientistas e investigadores capaces de continuar y fortalecer el pensamiento y las concepciones de los creadores del marxismo.

\section{SU LEGADO POLÍTICO PARTIDISTA}

Conocemos que Aguirre se había propuesto como uno de sus más caros anhelos, escribir la historia del socialismo en América Latina y el Ecuador. No alcanzó a cristalizarlo; sin embargo, sus múltiples aportes sobre el tema contienen elementos que nos permiten comprender la recia personalidad de quien, sin duda alguna, fue un hombre de partido.

De un partido sobre cuyo carácter y naturaleza de clase no dudó jamás; esto es, el partido de los trabajadores manuales e intelectuales, urbanos y rurales; un partido de raíz nacional, con plena autonomía internacional, que debe buscar permanentemente fundamentar su accionar en la continuidad histórica y política de las luchas de nuestro pueblo; un partido latinoamericanista y antimperialista que persigue construir una nueva sociedad y un nuevo tipo de Estado; un partido revolucionario, entendida la revolución como una verdadera transformación producto de un proceso ininterrumpido y no como un simple cambio de fichas en el viejo tablero político. (Marx ante América Latina, 1985, p. 109).

Esta revolución, decía, no puede estar conducida por la pequeña burguesía o clase media, heterogénea, inestable y vacilante, sino por el proletariado, aliado a la gran masa de campesinos pobres, a ciertos sectores revolucionarios de la pequeña burguesía, al semiproletariado, a las masas indígenas.

Con esta concepción, Aguirre condenó al colaboracionismo del partido socialista con los gobiernos de Guerrero Martínez y de Galo Plaza; se opuso terminantemente a que el partido formara parte de los frentes populares con la burguesía que no solo desvirtuaban el contenido del movimiento obrero sino que lo ponían al servicio de sus enemigos de clase (Íb., p. 124).

Esta oposición terminante a todo propósito de colaboración con la burguesía, en cuanto proviene de un dirigente político ligado a las luchas de los trabajadores, adquiere una connotación especial, como elemento demarcatorio entre las posiciones reformistas, socialdemócratas, proimperialistas y las posiciones transformadoras, populares, revolucionarias.

De igual manera, Aguirre rechazaba las ilusiones y utopías de una democracia burguesa y fraudulenta, pero sin caer en actitudes anarquizantes. Decía que la intervención electoral del partido debe ser apreciada no como un fin, sino como una simple forma de lucha y denuncia del sistema de explotación capitalista.

Simultáneamente, condenaba la actitud de los enemigos del proletariado, de los que temen realmente la revolución y buscan solo las inmediatas satisfacciones personales; de los que hablan que los obreros son ingratos, que no los siguen y votan por ellos. Estos falsos conductores quisieran, para considerar al proletariado latinoamericano y ecuatoriano como una fuerza conductora de la revolución, que estuvieran en mayoría, no precisamente para realizarla, sino para hacerlos triunfar en los torneos electorales que han de darles posiciones cómodas y prebendas. (América Latina y el Ecuador, 1959, p. 19). 
Aguirre no desmayó jamás en destacar la necesidad de que el partido trabaje en favor de lograr una férrea unidad de las masas en torno a un programa destinado a satisfacer los intereses esenciales de los trabajadores, en contra de las capas más poderosas de la clase dominante, del imperialismo y del Estado a su servicio.

\section{SU LEGADO ACERCA DE LA UNIVERSIDAD}

Una de las contribuciones más importantes de Aguirre es la referida al papel de la universidad que, si bien reconocía no es un todo monolítico, constituye una suerte de caja de resonancia que reproduce y registra en su microcosmos la vida entera del macrocosmos nacional e internacional.

Precisamente por el carácter subdesarrollado del país, por su estructura económico social de mosaico, por la agudeza de la penetración imperialista, por el enorme atraso político de la mayoría de los ecuatorianos, por las variadas características culturales del conglomerado nacional, Aguirre destacaba que toca a la universidad constituirse en el verdadero guía de la conciencia popular, en el verdadero líder indiscutible de su pueblo.

En el marco de su proyecto sobre Segunda Reforma Universitaria, tiene Aguirre tan esclarecedoras y actuales reflexiones, que es mejor simplemente transcribir parte de su pensamiento, a fin de que sean las propias ideas del autor y no mi interpretación, las que nos permitan situarlo debidamente.

La universidad tiene que encontrar en el pueblo los músculos de su acción y el pueblo en la universidad el instrumento intelectual de su liberación. La universidad no puede estar al servicio de las ideologías caducas, falsas, anticientíficas, ni soportar la férula de ningún dogma que encierre y encadene al espíritu. No la universidad dogmática, sino la universidad científica, abierta a la comprensión de las nuevas teorías y sistemas; no para introducirlas por la fuerza en los espíritus, sino por medio de la activa militancia, de la discusión libre y la razón plena. La universidad no puede vivir en el pasado sino en el presente y en el futuro, el futuro de un pueblo y sus destinos. Tiene que convertirse, a través de sus facultades, en la verdadera orientadora de la conciencia nacional en todos sus aspectos. La universidad tiene que ser cada vez más profundamente democrática, no solo internamente, sino en la vida pública. La universidad tiene que hacer política, pero no, asimismo, en el sentido vulgar que se da a la palabra, sino en el científico y auténtico de política con mayúsculas, como concepción y ciencia del Estado; no en el concepto, repetimos, de bandería o comité electoral, sino en formar a los hombres que deben servir en las funciones administrativas del Estado. La universidad tiene que enseñar y educar para la verdad y formar el carácter para decirla sin temores. Hemos vivido y estamos viviendo en un ambiente de falsedad, de farsa y de mentira. La inteligencia sin principios y sin carácter es siempre una amenaza real o latente para la sociedad, es ella la que está dispuesta a los bajos menesteres demagógicos; es ella la que traicionando a su pueblo, se vende a las oligarquías ignaras que lo oprimen, por dinero, por vanidad, por temor o por ambición.

Cuán aleccionadoras y oportunas resultan todas estas expresiones de Aguirre en el momento actual del país y de la universidad, cuando el capitalismo ecuatoriano ha vivido y vive una de las crisis más graves, profundas y persistentes de su historia moderna; cuando ese capitalismo está sometido a un proceso de reestructuración; cuando han ganado espacio las estrategias 
aperturistas, neoliberales; cuando la desocupación y subocupación han aumentado; cuando la inflación se ha incrementado; cuando la pobreza ha crecido.

Y justo cuando tales hechos se han presentado, la universidad permanece anquilosada, inmóvil, encerrada, ajena a los problemas del mundo y del Ecuador, secuestrada por fuerzas sectarias que se impusieron con una torpe violencia.

Pues hoy precisamente la universidad no puede ponerse al margen de los graves y difíciles problemas cuotidianos de la nación, sino sentirlos y vivirlos, aportando, con oportunidad, las más eficaces y mejores soluciones; no puede permanecer indiferente ante la miseria, el dolor y la incultura de su pueblo, porque la indiferencia, la fétida indiferencia, como se ha dicho, no es sino una forma disfrazada de pertenecer o servir a la clase de los saciados, de los que tienen todo.

Hoy las universidades, especialmente las estatales ecuatorianas, requieren algo más que una transferencia adecuada de recursos y, por supuesto, sus profesores y personal administrativo de mucho más que pagos oportunos de sus sueldos. Hoy las universidades estatales necesitan preocuparse por los problemas mundiales y del país e inquietarse en forma muy especial por el deterioro del sistema educativo público, la elitización de la educación, la pretensión de la dase dominante ecuatoriana de «modernizar» a su manera a las universidades nacionales.

\section{SU LEGADO LATINOAMERICANISTA}

Tanto en sus concepciones teóricas cuanto en su práctica, Aguirre se mostró como un notable latinoamericanista, fue un internacionalista ejemplar. A ello contribuyó su profunda convicción antimperialista. Decía que los países subdesarrollados o semicolonialistas no pueden de ninguna manera, dadas las actuales condiciones históricas del mundo, recorrer el camino que siguieron los hoy grandes países capitalistas como Inglaterra y los Estados Unidos que gozaron, por otra parte, de circunstancias excepcionales; ni alcanzar ningún desenvolvimiento con los métodos capitalistas en un mundo monopolista e imperialista que no ofrece ninguna posibilidad de desanollo a los países coloniales y semicoloniales, a los que les interesa mantener como productores de materias primas y mercado para sus productos manufacturados (Teoría y Acción Socialistas, p. 16). Abundando en estos conceptos, Aguirre subrayaba que:

$\mathrm{Al}$ imperialismo le interesa mantener las formas atrasadas de producción. ¿Acaso no sabemos que actualmente la economía latinoamericana y especialmente ecuatoriana, continúan encadenadas al comercio exterior de exportación e importación, que es el que les impone su ritmo y su modalidad esencial? Después del gran desarrollo mundial del capitalismo y el advenimiento del imperialismo, las naciones no pueden considerarse como unidades aisladas e independientes, sino como simples eslabones, débiles o fuertes del gran capitalismo mundial; [por lo mismo,] en esta etapa de integración e internacionalización del capital y de las burguesías transnacionales y nacionales, [... ]la revolución adquiere un necesario e ineludible carácter continental, al que tenemos que integramos todos los verdaderos partidos socialistas revolucionarios. (Marx ante América Latina, 1985, p. 128)

Es decir, Aguirre comprendía que el desarrollo de América Latina exigía una lucha contra el imperialismo. Esta concepción antimperialista, su sentido latinoamericanista e internacionalista, 
supo traducirlos en el ejemplar y solidario desempeño en la presidencia del comité nacional de apoyo a los exiliados chilenos y argentinos reprimidos y expulsados por Pinochet y Videla; en la firme y permanente defensa de la Revolución Cubana; en el respaldo - aunque no acrítico ni obsecuente - a la comunidad de países socialistas.

Me he referido a cuatro legados principales que nos han dejado el pensamiento y la obra de Manuel Agustín Aguirre; sin embargo, puedo destacar que toda su vida constituye una extraordinaria como generosa donación que debemos preservar y enaltecer.

Insisto que Aguirre vivió sus últimos años — cuando su producción intelectual y política fue sin duda más fecunda - una fase en la cual el desarrollo del capitalismo a nivel mundial empezó a debilitarse y a soportar crisis cada vez más profundas. Vivió cuando las contradicciones capitalistas más agudas estallaron en dos guerras mundiales devastadoras y funestas. Vivió cuando se produjo la revolución cubana, a noventa millas de la principal potencia imperialista mundial; cuando inclusive y como resultado de este tipo de fenómenos, se produjeron considerables avances en las luchas de liberación nacional y cuando el ascenso del socialismo parecía ininterrumpido, definitivo, permanente.

Como resultado de estas condiciones mundiales y latinoamericanas Aguirre probablemente consideró inminente la descomposición más acelerada del capitalismo y la victoria del socialismo. Por lo tanto, es posible que, en este contexto y ante el principal propósito de concentrar su atención en destacar el carácter capitalista de la formación social ecuatoriana, Aguirre haya eventualmente prescindido de un análisis más específico del proceso histórico nacional, desechando una consideración más profunda sobre los diferentes cambios sufridos por el capitalismo ecuatoriano en su desarrollo histórico.

Es incluso probable que en una etapa aún temprana del proceso ecuatoriano, cuando se carecía de información y se trataba de temas que nacionalmente todavía eran poco discutidos, Aguirre haya puesto más énfasis en múltiples aspectos teóricos antes que en otros referidos a nuestra específica y siempre cambiante realidad nacional.

No cabe olvidar, por otro lado, que la principal actividad de creación y difusión intelectual, teórica, ideológica, política de Aguirre, estuvo concentrada en los decenios del 50, 60 y primeros años del 70 del siglo pasado; mientras que el desarrollo vertiginoso del capital monopolista y del capital monopolista de Estado en el Ecuador, fueron simultáneos con la exportación petrolera, la afluencia de capital extranjero, el crecimiento de la industria y del sistema financiero, la ampliación del mercado interno, la mayor inserción del país en el mercado mundial.

Se unieron pues a la firmeza de las convicciones ideológicas y políticas, al carácter incorruptible, insobornable e indoblegable de la personalidad de Aguirre, condiciones materiales objetivas que hacían presagiar un ascenso victorioso del socialismo. Por consiguiente, en este contexto, se explica el énfasis que Aguirre depositaba en la acción política estratégica y en la escasa utilización de categorías tan importantes como capital monopolista y capital monopolista de Estado, que figuran poco en sus penetrantes análisis.

Pero las perspectivas de un ascenso victorioso del socialismo, presentes hasta bien avanzada la década de los 70 del siglo pasado, empezaron a debilitarse a partir fundamentalmente de 1980, cuando en América Latina surgió lo que más tarde se conoció como la «década rerdida»; cuando se produjo la derrota de la Unidad Popular que llevó a Allende al poder en 
Chile; cuando empezó a incubarse el fracaso de la Revolución Sandinista en Nicaragua y cuando a nivel mundial se hicieron presentes enormes dificultades que condujeron a la descomposición de la Unión Soviética y el retomo del capitalismo en los países exsocialistas de la Europa del Este.

Desconozco si en los últimos años de su vida, Aguirre dispuso de tiempo y disposición para examinar estos problemas; sin embargo, es evidente que a él como a todos quienes apreciábamos los notables esfuerzos del pueblo soviético que en el clímax de su lucha supo destruir a la supuesta invencibilidad del nazifascismo, le afectaron y nos afectaron profundamente este tipo de acontecimientos; mas Aguirre jamás abjuró de sus principios ni mucho menos abrazó las posiciones del socorrido oportunismo político.

Como quiera que sea, nadie puede negar que en los cuatro o seis años anteriores han sucedido en el mundo hechos muy importantes como una intensificada reestructuración y creciente internacionalización del capital, la crisis y desaparición de la comunidad socialista, la cambiante y más desfavorable correlación de fuerzas revolucionarias a nivel mundial, la conformación y fortalecimiento de poderosos bloques económicos regionales, la imposición a nuestros países de políticas aperturistas, neoliberales.

Frente a estos y muchos otros acontecimientos, cuya significación es inútil negar, hoy surgen por doquier verdaderos sepultureros del socialismo que se empeñan en glorificar al capitalismo, que no se cansan de pregonar que el socialismo ha fracasado; que se esmeran en repetir que solo el capitalismo ha demostrado ser creativo, eficiente, imaginativo, superior, eterno.

Pero lo que no se dice o lo que suelen ocultar los apologistas del capitalismo, es que la significativa trascendencia de los cambios internacionales no ha trastocado las leyes básicas del desarrollo social, no han hecho desaparecer a la concentración y centralización del capital, no han terminado con las contradicciones capital trabajo, no han disuelto las causas de la crisis y de la explotación.

Más bien se puede sostener que la desintegración de la Unión Soviética, el fracaso del socialismo y la persistencia y agravamiento de las crisis capitalistas, ponen hoy claramente en evidencia que no ha sido la acción del socialismo, sino las contradicciones insalvables del capitalismo y del imperialismo las que explican la situación de pobreza, de desempleo, de inflación, de deterioro ambiental, de corrupción, de antidemocracia que se extienden por todas partes del mundo.

En el orden nacional, se puede asimismo advertir que los cambios mundiales, no han creado condiciones para que el Ecuador pueda emprender una vía de desarrollo capitalista análoga a la seguida por los Estados Unidos, Europa o Japón; tampoco para que nuestro país ingrese airosamente en el bloque de países primer mundistas. La reconstitución del capitalismo y el derrumbe del socialismo en los países de la Europa Central y del Este, no ha alterado la incapacidad histórica de la burguesía ecuatoriana para actuar en favor de los intereses del pueblo.

Las políticas neoliberales de ajuste, de estabilización, de achicamiento del Estado, de cambio estructural, no han sido capaces de ofrecer a los trabajadores un crecimiento económico estable, empleo y niveles de ingreso mínimos, ni mucho menos sentar las bases para, en el mediano y largo plazos, superar el atraso y avanzar en la satisfacción de las necesidades esenciales de la población nacional. 
Por lo mismo, quienes estamos convencidos de que en el marco del capitalismo no hay posibilidad alguna de resolver los fundamentales problemas del conjunto del pueblo, debemos trabajar en la perspectiva de conformar un nuevo bloque de fuerzas sociales y políticas capaces de resistir la ofensiva neoliberal y para avanzar en la forja de una nueva estrategia de poder, actuando simultáneamente no solo en el plano estratégico sino en el táctico, demostrando que los trabajadores no han sido ganados por el conformismo, la desconfianza, la pasividad.

Ahora bien, conscientes de estas apreciaciones, es evidente también que la izquierda ecuatoriana, el socialismo, están en la obligación de renovarse, de prepararse mejor para responder eficazmente a las exigencias de una lucha ideológica más difícil y compleja. Hoy es imperioso proceder con mayor flexibilidad, lo cual de ninguna manera significa abrir espacios para la subordinación de los trabajadores a un Estado al servicio fundamentalmente de la burguesía nativa y trasnacional, ni para contemporizar de manera oportunista con los enemigos del pueblo.

Hoy es importante usar nuevos métodos de organización y de contacto con la gente, aglutinar a nuevas fuerzas, inclusive a hombres y mujeres no organizados. Es necesario abandonar las tendencias parlamentaristas superficiales e inconducentes. Es vital terminar con ciertas prácticas antidemocráticas presentes en varias organizaciones populares y partidos de izquierda. Es fundamental acabar con esa actitud de menosprecio que determinadas personas demuestran y ejercen frente a quienes no se suman y hasta se subordinan a sus intereses y decisiones.

En la perspectiva de hacer todo lo supuesto, hoy es evidente la necesidad que tenemos de evaluar experiencias históricas, recoger enseñanzas, reapreciar críticamente de manera creadora y fresca toda la lucha política de nuestros más destacados dirigentes. Hoy es indispensable recoger el pensamiento, la ruta rectilínea e insobornable y la actitud vital que mantuvo Manuel Agustín Aguirre durante su actividad polifacética.

Recoger el pensamiento y la acción de Aguirre no de manera habitual, formalista o de rutina, sino como algo propio de un ecuatoriano ejemplar, de un hombre de su tiempo cuya obra ha sido capaz de proyectarse hacia el futuro y - en múltiples aspectos- encontrarse plenamente vigente. Un hombre de una fuerza moral indoblegable, de una decisión inquebrantable, de una convicción revolucionaria increíble. Un hombre proverbialmente honrado, frugal, modesto, riguroso consigo mismo. Un hombre profundamente humano que supo vivir con ejemplar dignidad y enriquecer el patrimonio cultural y político de nuestro pueblo.

No obstante la avanzada edad y la discreta presencia pública que en los últimos años Aguirre prefirió mantener, es evidente que en razón de la hondura de su pensamiento y de los proyectos que hasta el final acarició, su muerte privó al país de un aporte esencial.

En uno de sus últimos discursos, el pronunciado en Loja en abril de 1987 agradeciendo un homenaje que le tributaran la Casa de la Cultura Ecuatoriana núcleo de Loja, la prefectura, la alcaldía, las universidades de esa provincia y ciudad y la vicepresidencia del Congreso Nacional, Manuel Agustín Aguirre dijo algo que hoy merece ser subrayado:

Hay que olvidar mucho del pasado, no hay que dejar que los muertos manden. [...] Hay nombres que deben desaparecer, pero hay otros que debemos mantenerlos en el recuerdo porque son nuestra historia y son nuestra propia vida. 
Aguirre es precisamente uno de aquellos hombres a los cuales siempre los mantendremos en el recuerdo, conscientes inclusive de que bajo la sombra de su acción y de su pensamiento, muchos pretendieron legitimar actitudes sin duda condenables, como las de cultivar en la juventud especialmente universitaria, prácticas de manipulación, de componendas, de facilismo, de servilismo, de intriga, de corrupción.

La muerte de Aguirre, sin embargo, hoy pone a quienes bajo su nombre pretendieron legitimar acciones impropias, a moverse sin tutelas, los pone y nos pone a todos quienes apreciamos con respeto su valiente posición, en la imperiosa necesidad de pensar y decidir en función de ideas e intereses que respondan al anhelo de construir el futuro que él avisoró. Creo que es deber de todos quienes conocimos y apreciamos la vida de Aguirre, poner todo nuestro empeño en contribuir con autonomía a la construcción de un Ecuador superior, de un Ecuador socialista.

Quito, 20 de noviembre de 1992 